\title{
Simultaneous Presence of Acetylcholine Receptor and Muscle Specific Tyrosine Kinase Antibodies in Myasthenia Gravis
}

\author{
Maryam Poursadeghfard ${ }^{1 *}$, Sara Azhdari ${ }^{2}$ \\ ${ }^{1}$ Clinical Neurology Research Center, Department of Neurology, Medical School, Shiraz University of Medical Sciences, \\ Shiraz, Iran \\ ${ }^{2}$ Department of Neurology, Medical School, Shiraz University of Medical Sciences, Shiraz, Iran
}

\section{*Correspondence to Maryam Poursadeghfard, MD, \\ Clinical Neurology Research Center, Department of Neurology, Medical School, Shiraz University of Medical Sciences, Shiraz, Iran, \\ Tel: +98 7136121065 , Mobile: +98917 3149879, \\ Email: poursadegh@sums.ac.ir, Poursadra@gmail.com \\ Received November 8, 2019 Accepted December 21, 2019 Published online December 31, 2019

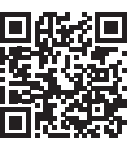

Please cite this article as follows: Poursadeghfard M, Azhdari S

Simultaneous Presence of Acetylcholine Receptor and Muscle Specific Tyrosine Kinase Antibodies in Myasthenia Gravis: A Case Report. Int J Basic Sci Med. 2019;4(4):128-130. doi:10.34172ijbms.2019.01

\begin{abstract}
Myasthenia gravis (MG) is known as an autoimmune disorder which affects transmission in neuromuscular junction. The serologic tests used for diagnosis include acetylcholine receptor and muscle specific receptor tyrosine kinase antibodies. Studies often have reported that patients with formal antibody are negative for the latter one. However, very limited studies have reported positive anti-muscle specific receptor tyrosine kinase antibody in a small percentage of patients with acetylcholine receptor antibody. Here, we reported a young woman who was diagnosed with MG and had a rapid and progressive course of the disease. She was seropositive for both acetylcholine receptor and muscle-specific receptor tyrosine kinase antibodies simultaneously. However, she discharged from the hospital with good condition after treatment.

Keywords: Myasthenia gravis, Acetylcholine receptor antibody, Muscle-specific receptor tyrosine kinase
\end{abstract}

\section{Introduction}

Myasthenia gravis (MG) is known as an autoimmune disorder which affects the transmission in neuromuscular junction. The disease is characterized by ocular, bulbar, limb and respiratory muscle weakness. ${ }^{1,2}$ In addition to history taking and physical examination, confirmatory tests including bedside ice pack, intravenous edrophonium chloride, and serologic tests are usually needed. In clinical practice, two important serologic tests are acetylcholine receptor antibody $(\mathrm{AChR}-\mathrm{Ab})$ and antibody against muscle specific receptor tyrosine kinase (MuSKAb). ${ }^{3,4}$

AChR-Ab is observed in about $85 \%$ of the MG patients with the generalized form of the disease. ${ }^{5}$ Recent researches have reported the role of MuSK antibody in the pathogenesis of the disease and some distinct clinical features of the patients with MG. On the other hand, this antibody tends to be more prevalent in younger age groups and females. ${ }^{6-10}$ However, according to basic immunology, few reports have declared positive MuSK antibody in a small percentage of the seropositive patients for AChR-Ab. ${ }^{11}$

In this paper, we report a young woman who was diagnosed with $\mathrm{MG}$ and was seropositive for both AChR and MuSK antibodies simultaneously which is a very unusual condition in MG.

\section{Clinical Presentation}

History and Physical Examination

A 25-year-old woman presented with chief complaints of generalized weakness, ptosis, and dysphagia. Her symptoms had started 3 months before her referral and worsened during the last week before admission to the hospital. The patient had no history of the previous admission to hospital and

(c) 2019 The Author(s); Published by Zabol University of Medical Sciences. This is an open-access article distributed under the terms of the Creative Commons Attribution License (http://creativecommons.org/licenses/by/4.0), which permits unrestricted use, distribution, and reproduction in any medium, provided the original work is properly cited. 
autoimmune, systemic or metabolic diseases. She was not under treatment with any other medications. Moreover, she did not report using any herbal medications. Family history was negative for similar episodes of weakness or other specific diseases.

\section{Laboratory Results}

Complete blood count, blood urea nitrogen (BUN) and creatinine level, electrolytes including sodium, potassium, calcium, and magnesium level, fasting plasma glucose, and liver function tests were all normal. The thyroid function test was also normal.

\section{Course of the Disease}

During hospitalization, the patient's condition rapidly worsened and she developed respiratory failure. The patient was intubated in the intensive care unit and respiratory support was provided using ventilator.

\section{Treatment and Follow-up}

Intravenous immunoglobulin (IvIg) was administered to the patients at a total dose of $125 \mathrm{~g}(0.4 \mathrm{~g} / \mathrm{kg} / \mathrm{d})$ for 5 days. The patient responded poorly to the treatment. Therefore, we initiated treatment with plasmapheresis. The response to plasmapheresis was excellent and the patient's condition got better. She was discharged with good general condition after the disappearance of all the symptoms.

\section{Confirmation of the Diagnosis}

The spiral chest CT scan showed no abnormality in the thymus gland. Repetitive nerve stimulation suggested post-synaptic neuromuscular junction disorder. AntiMuSK and -AchR antibodies were 9.3 and $4.31 \mathrm{U} / \mathrm{mL}$, respectively (Normal range was $<0.4 \mathrm{U} / \mathrm{mL}$ for both indexes).

\section{Discussion}

The patient was seropositive for both anti-AChR and MuSK antibodies with symptoms mainly mimicking MuSK-Ab positive MG. AChR-Ab is reported in about $85 \%$ of MG patients with the generalized form of the diseases. ${ }^{5}$ There is a poor association between the severity of illness and the titer of AChR-Ab. However, in patients who are seropositive for AChR-Ab, the decrease in the titer of AChR-Ab is associated with clinical improvement. In addition, almost all patients with thymoma are seropositive for AchR-Ab. ${ }^{12}$

MuSK is an enzyme which acts as a supporter of the post-synaptic membrane and participates in the clustering of AChR in neuromuscular junction development. ${ }^{13}$ This autoantibody is predominantly the IgG4 subclass and its titer is associated with the severity of the disease. IgG4 does not affect the complement system, unlike the IgG1 and IgG3 subclasses of AChR antibodies. ${ }^{14}$ It is shown that patients with MuSK-Ab are clinically different from
AChR-Ab positive patients. ${ }^{6}$ The oculobulbar form is more common than the pure ocular form in MuSK-Ab positive patients. ${ }^{15}$ Additionally, restricted myopathic presentations including respiratory and proximal muscles weakness are more expected in MuSK-Ab positive patients. No thymic pathology was reported in this group. The response to acetylcholinesterase inhibitors is poor and these patients respond well to immunosuppression and plasma exchange. ${ }^{16}$

Most studies on MG patients have reported that patients with the AChR-Ab are seronegative for MuSK-Ab.-10 However, few studies have reported positive MuSK-Ab in a small percentage of $\mathrm{MG}$ patients with AChR-Ab. Ohta et al showed a laboratory association of the anti-AChR and anti-MuSK antibodies in some patients with MG using a new recombinant protein of the extracellular domains of human MuSK which could detect the presence of antiMuSK antibody besides the AChR-Ab in MG. However, in the standard rout, radioimmunoprecipitation test or ELISA is usually used to detect the MuSK-Ab ${ }^{11}$

In another study published in 2012, Poulas et al checked 1127 MG patients for the AChR and MuSK antibodies and identified one double-positive patient and three patients with positive anti-MuSK antibody and suspected anti-AChR antibody positivity. In all of them, anti-AChR antibody titers were much lower than the anti-MuSK antibody titers. In this paper, they also presented a new case of scleroderma who developed MG with double autoantibodies. ${ }^{17}$ In our case, the anti-MuSK antibody titer was also two times higher than the anti-AChR antibody titer.

In this case, in spite of the simultaneous presence of both antibodies, it seems that clinical presentations and treatment response were more similar to MuSK-Ab positive patients. The factors confirming this fact are the young age of the patient, predominant and rapidly progressive respiratory symptoms, patient's gender and fair response to IvIg in contrast to a good response to plasmapheresis.

\section{Conclusion}

According to this experience, we recommend that the patients who are seropositive for AChR-Ab are also better to be checked for MuSK antibodies when they are young females and present with respiratory symptoms, a rapidly progressive course, and fair response to IvIg.

\section{Ethical Approval}

Informed consent was obtained from the patient to publish this report.

\section{Conflict of Interest Disclosure}

The authors reported that they have no conflict of interests. 


\section{Acknowledgements}

The authors would like to thank Shiraz University of Medical Sciences, Shiraz, Iran, and Center for Development of Clinical Research of Nemazee Hospital as well as Dr. Nasrin Shokrpour for editorial assistance.

\section{References}

1. Lau AY, Chan AY, Mok VC. Refractory bulbar and respiratory dysfunction in a young Chinese woman with seronegative, muscle-specific tyrosine kinase antibodypositive myasthenia gravis: response to cyclophosphamide and rituximab treatment. Hong Kong Med J. 2011;17(1):7779.

2. Lee SJ, Hur J, Lee TW, et al. Myasthenia gravis presenting initially as acute respiratory failure. Respir Care. 2015;60(1):e14-16. doi:10.4187/respcare.03210

3. Tamer S, Gokce Gunes HN, Gokcal E, Yoldas TK. Coexistence of autoimmune diseases and autoantibodies in patients with myasthenia gravis. Neurol India. 2016;64(1):45-49. doi:10.4103/0028-3886.173638

4. Mahajan SK, Singh JB, Gupta P, Dogra V, Kapoor D. Ice pack test in myasthenia gravis. J Assoc Physicians India. 2014;62(6):516-517.

5. Vernino S, Lennon VA. Autoantibody profiles and neurological correlations of thymoma. Clin Cancer Res. 2004;10(21):7270-7275. doi:10.1158/1078-0432.ccr-040735

6. Deymeer F, Gungor-Tuncer O, Yilmaz V, et al. Clinical comparison of anti-MuSK- vs anti-AChR-positive and seronegative myasthenia gravis. Neurology. 2007;68(8):609611. doi:10.1212/01.wnl.0000254620.45529.97

7. McConville J, Farrugia ME, Beeson D, et al. Detection and characterization of MuSK antibodies in seronegative myasthenia gravis. Ann Neurol. 2004;55(4):580-584. doi:10.1002/ana.20061

8. Sanders DB, El-Salem K, Massey JM, McConville J, Vincent A. Clinical aspects of MuSK antibody positive seronegative MG. Neurology. 2003;60(12):1978-1980. doi:10.1212/01. wnl.0000065882.63904.53

9. Vincent A, McConville J, Farrugia ME, NewsomDavis J. Seronegative myasthenia gravis. Semin Neurol. 2004;24(1):125-133. doi:10.1055/s-2004-829589

10. Nemoto Y, Kuwabara S, Misawa S, et al. Patterns and severity of neuromuscular transmission failure in seronegative myasthenia gravis. J Neurol Neurosurg Psychiatry. 2005;76(5):714-718. doi:10.1136/jnnp.2004.043125

11. Ohta K, Shigemoto K, Kubo S, et al. MuSK antibodies in AChR Ab-seropositive MG vs AChR Ab-seronegative MG. Neurology. 2004;62(11):2132-2133. doi:10.1212/01. wnl.0000129274.12702.92

12. Choi Decroos E, Hobson-Webb LD, Juel VC, Massey JM, Sanders DB. Do acetylcholine receptor and striated muscle antibodies predict the presence of thymoma in patients with myasthenia gravis? Muscle Nerve. 2014;49(1):30-34. doi:10.1002/mus.23882

13. El-Salem K, Yassin A, Al-Hayk K, Yahya S, Al-Shorafat D, Dahbour SS. Treatment of MuSK-Associated Myasthenia Gravis. Curr Treat Options Neurol. 2014;16(4):283. doi:10.1007/s11940-014-0283-8

14. Guptill JT, Sanders DB. Update on muscle-specific tyrosine kinase antibody positive myasthenia gravis. Curr Opin Neurol. 2010;23(5):530-535. doi:10.1097/ WCO.0b013e32833c0982

15. Scuderi F, Marino M, Colonna L, et al. Anti-p110 autoantibodies identify a subtype of "seronegative" myasthenia gravis with prominent oculobulbar involvement. Lab Invest. 2002;82(9):1139-1146. doi:10.1097/01.lab.0000028144.48023.9b

16. Evoli A, Tonali PA, Padua L, et al. Clinical correlates with anti-MuSK antibodies in generalized seronegative myasthenia gravis. Brain. 2003;126(Pt 10):2304-2311. doi:10.1093/brain/awg223

17. Poulas K, Koutsouraki E, Kordas G, Kokla A, Tzartos SJ. Anti-MuSK- and anti-AChR-positive myasthenia gravis induced by d-penicillamine. J Neuroimmunol. 2012;250(12):94-98. doi:10.1016/j.jneuroim.2012.05.011 